\title{
Platelet and Erythrocyte Indexes in Complex Regional Pain Syndrome Type I
}

\author{
Alparslan YETIŞ̧İN, Ahmet TUTOĞLU, Abdülhalik CİNAKLI, Mahmut KUL, Ahmet BOYACI \\ Department of Physical Medicine and Rehabilitation, Medical Faculty of Harran University, Şanlıurfa, Turkey
}

\begin{abstract}
Objectives: This study aims to compare the levels of platelet and erythrocyte indexes including mean platelet volume, platelet distribution width (PDW), and red blood cell distribution (RDW) values between complex regional pain syndrome (CRPS) type I patients and healthy controls to establish a marker of neuroinflammation that might be a potential factor involved in CRPS etiopathogenesis.

Patients and methods: A total of 21 patients (14 males, 7 females; mean age $35.0 \pm 15.4$ years; range 15 to 69 years) with a diagnosis of CRPS type I

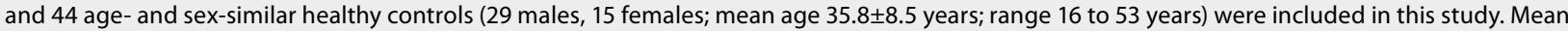
platelet volume, PDW, RDW, white blood count, hemoglobin, erythrocyte sedimentation rate, and C-reactive protein levels, and neutrophil to lymphocyte ratio and thrombocyte to lymphocyte ratio were compared between the patient and control groups.

Results: No differences were noted between patient and control groups in terms of erythrocyte sedimentation rate and C-reactive protein levels, white blood cell, neutrophil, lymphocyte and thrombocyte counts, and neutrophil to lymphocyte and thrombocyte to lymphocyte ratios (all $p>0.05)$. When compared with controls, patients had significantly higher mean corpuscular volume $(p=0.019)$ and RDW $(p=0.002)$ values, and a lower PDW level $(p=0.006)$.

Conclusion: Differences in PDW, RDW, and mean corpuscular volume values between patients and controls might support the potential role of neuroinflammation in the etiopathogenesis of CRPS type I. Prospective studies with larger sample sizes are warranted in the early detection and differential diagnosis of CRPS type I.

Keywords: Complex regional pain syndrome; erythrocyte; neuroinflammation; platelet.
\end{abstract}

Complex regional pain syndrome (CRPS) is a clinical condition characterized by symptoms such as pain, swelling, allodynia, and dysesthesia. It usually develops at the distal of an affected extremity after trauma., ${ }^{1,2}$ CRPS is classified into two types, and the main difference between them is that type II develops after a peripheral nerve injury. The major symptom is severe and usually burning type of neuropathic pain that is inconsistent with the triggering factor. While the etiology of CRPS may include different entities such as trauma, cerebrovascular event (CVE), myocardial infarction, and inflammatory diseases, it may also occur idiopathically. ${ }^{1}$ Although diagnosis of CRPS can be established based on anamnesis and physical examination, imaging methods such as radiography, magnetic resonance imaging, and three-phase bone scintigraphy may be useful in case of any doubt. However, these methods are not commonly used for diagnostic purposes as they have different sensitivities and are not specific to CRPS. ${ }^{1}$

Several factors including neurogenic inflammation, peripheral sensitization, reorganization of Amyloid beta filaments, central sensitization, sympathetic dysfunction, ectopic discharge, and microvascular dysfunction have been held responsible for the pathogenesis of CRPS type I. $^{3-9}$ In order to demonstrate its potential role in CRPS pathogenesis, neurogenic

Received: April 12, 2016 Accepted: April 25, 2016 Published online: April 26, 2016

Correspondence: Alparslan Yetişgin, MD. Harran Üniversitesi Tıp Fakültesi Fiziksel Tıp ve Rehabilitasyon Anabilim Dalı, 63300 Şanlıurfa, Turkey.

Tel: +90 414 - 3444131 e-mail: dra_yetisgin@yahoo.com

@2016 Turkish League Against Rheumatism. All rights reserved. 
inflammation has been investigated in a limited number of studies. However, to our knowledge, there is no significant finding regarding the diagnostic value of the conventional inflammatory markers including erythrocyte sedimentation rate (ESR), C-reactive protein (CRP), white blood cell count, and several other sophisticated parameters such as tumor necrosis factor alpha and interferon gamma. ${ }^{10,11}$

In previous studies including patients with multiple sclerosis (MS) and Alzheimer's disease (AD) where neuroinflammation plays a crucial role in the disease etiopathogenesis, changes have been reported in mean platelet volume (MPV), platelet distribution width (PDW), and red blood cell distribution (RDW) values. ${ }^{12-14} \mathrm{MPV}$, PDW, and RDW are the parameters that reflect thrombocyte size, heterogeneity and activation of the thrombocytes, and the variations in erythrocyte size/volume, respectively. ${ }^{13,14}$ On the other hand, to the best of our knowledge, there is no study investigating the alterations of these parameters in patients with CRPS.

Accordingly, in this study, we aimed to compare the levels of platelet and erythrocyte indexes including MPV, PDW, and RDW values between CRPS type I patients and healthy controls to establish a marker of neuroinflammation that might be a potential factor involved in CRPS etiopathogenesis.

\section{PATIENTS AND METHODS}

A total of 21 patients (14 males, 7 females; mean age $35.0 \pm 15.4$ years; range 15 to 69 years) diagnosed as CRPS type I according to Budapest criteria ${ }^{15}$ and 44 age- and sex-similar healthy controls (29 males, 15 females; mean age $35.8 \pm 8.5$ years; range 16 to 53 years) were included in this cross-sectional case-control study. Patients who admitted to Physical Medicine and Rehabilitation outpatient policlinics of Harran University Medical Faculty between January 2014 and January 2016 with CRPS complaints that started less than six months ago, and patients with normal ESR, CRP, white blood cell, thrombocyte count, and hemoglobin levels were enrolled. Antecubital venous blood samples were taken in morning after overnight fasting into hemogram, ESR, and biochemistry analyzing tubes. The biochemistry analyzing tubes were centrifuged at $1.500 \mathrm{rpm}$ for 10 minutes to obtain serum samples for the measurements of CRP.

Patients with a systemic inflammatory/hematooncological disease and those with an acute infection were excluded. ESR values below age/2 in males and (age+10)/2 in females, and CRP levels between $0.01-0.5 \mathrm{mg} / \mathrm{dL}$ were considered to be within normal limits. MPV, PDW, RDW, white blood count, hemoglobin, ESR and CRP levels, and neutrophil to lymphocyte ratio and thrombocyte to lymphocyte ratio were compared between the patient and control groups. The study was initiated after approval was obtained from Harran University Medical Faculty Ethics Committee. A written informed consent was obtained from each patient. The study was conducted in accordance with the principles of the Declaration of Helsinki.

\section{Statistical analysis}

All of the collected data were transferred into PASW version 18.0 software (SPSS Inc., Chicago, IL, USA). Data are given as mean \pm standard deviation. Kolmogorov-Smirnov test was used to determine whether variables were distributed normally or not. Numeric data were compared by using Student's t test or MannWhitney U test, where appropriate. Chi-square test was used to compare the categorical variables. A $p$ value $<0.05$ was considered as significant difference.

\section{RESULTS}

Demographical characteristics and laboratory findings are shown in Table 1. CRPS was posttraumatic in 19 patients and developed after a CVE in two patients. Mean age and sex distribution were similar between the patient and control groups (both p $>0.05$ ). Similarly, no differences were noted between the groups in terms of ESR and CRP levels, white blood cell, neutrophil, lymphocyte and thrombocyte counts, and neutrophil to lymphocyte and thrombocyte to lymphocyte ratios (all $\mathrm{p}>0.05$ ). When compared with controls, patients had significantly higher mean corpuscular volume (MCV) $(p=0.019)$ and RDW $(p=0.002)$ values, and a lower PDW level $(p=0.006)$. 


\begin{tabular}{|c|c|c|c|c|c|}
\hline & \multicolumn{2}{|c|}{ Patients $(n=21)$} & \multicolumn{2}{|c|}{ Controls $(n=44)$} & \multirow[b]{2}{*}{$p$} \\
\hline & $\mathrm{n}$ & Mean \pm SD & $\mathrm{n}$ & Mean \pm SD & \\
\hline Age (years) & & $35.0 \pm 15.4$ & & $35.8 \pm 8.5$ & 0.807 \\
\hline Sex & & & & & 0.952 \\
\hline Male & 14 & & 29 & & \\
\hline Female & 7 & & 15 & & \\
\hline White blood count $\left(\times 10^{9} / \mathrm{L}\right)$ & & $8.1 \pm 1.3$ & & $7.9 \pm 1.2$ & 0.398 \\
\hline Neutrophil count $\left(\times 10^{9} / \mathrm{L}\right)$ & & $4.3 \pm 1.1$ & & $4.3 \pm 1.0$ & 0.836 \\
\hline Lymphocyte count $\left(\times 10^{9} / \mathrm{L}\right)$ & & $3.0 \pm 0.7$ & & $2.7 \pm 0.5$ & 0.236 \\
\hline Neutrophil/lymphocyte & & $1.6 \pm 0.6$ & & $1.6 \pm 0.5$ & 0.787 \\
\hline Hemoglobin $(\mathrm{g} / \mathrm{dL})$ & & $15.2 \pm 1.5$ & & $14.9 \pm 1.5$ & 0.575 \\
\hline Mean corpuscular volume (fL) & & $88.1 \pm 4.8$ & & $85.1 \pm 4.6$ & 0.019 \\
\hline Red cell distribution width (\%) & & $12.5 \pm 0.8$ & & $11.8 \pm 0.9$ & 0.002 \\
\hline Thrombocyte count $\left(x 10^{9} / \mathrm{L}\right)$ & & $283.8 \pm 62.5$ & & $288.8 \pm 55.7$ & 0.750 \\
\hline Mean platelet volume (fL) & & $7.3 \pm 1.0$ & & $7.7 \pm 1.4$ & 0.352 \\
\hline Platelet distribution width (fL) & & $19.1 \pm 0.9$ & & $19.8 \pm 0.9$ & 0.006 \\
\hline Thrombocyte/lymphocyte & & $102.3 \pm 34.7$ & & $108.6 \pm 28.4$ & 0.472 \\
\hline Erythrocyte sedimentation rate $(\mathrm{mm} / \mathrm{hr})$ & & $9.4 \pm 6.8$ & & $9.0 \pm 6.1$ & 0.779 \\
\hline C-reactive protein $(\mathrm{mg} / \mathrm{dL})$ & & $0.1 \pm 0.1$ & & $0.1 \pm 0.1$ & 0.557 \\
\hline
\end{tabular}

\section{DISCUSSION}

In the present study, we aimed to investigate erythrocyte and thrombocyte indexes including MPV, PDW, and RDW values as markers of neuroinflammation in patients with CRPS type I. When compared with control group, patient group had significantly lower PDW, and higher RDW and $\mathrm{MCV}$ values.

As one of the factors believed to be involved in the pathogenesis of CRPS type I, neuroinflammation may be defined as the inflammatory response given by the brain and spinal cord. ${ }^{16-18}$ Neuroinflammatory response is mediated by proinflammatory cytokines (interleukin 1 beta, interleukin 6, and tumor necrosis factor alpha), certain chemokines, secondary messengers (prostaglandins and nitric oxide), and reactive oxygen species. ${ }^{16}$ Neuroinflammation is one of the significant factors playing role in the development of chronic neurodegenerative diseases such as Parkinson's and $\mathrm{AD}$, as well as acute neurological events including CVE and trauma. ${ }^{19,20}$ It is believed that brain cells trigger neuroinflammation in response to stress and acute events, causing cell damage/death and therefore leading to functional incapabilities, behavioral disturbances, and autonomic imbalance. ${ }^{19}$ Unlike systemic inflammatory response, neuroinflammation does not result in an increase in acute phase proteins; therefore, other potential markers of the presence/severity of neuroinflammation have been sought.

In a review on CRPS, ${ }^{21}$ there was very limited histological evidence of usual inflammation in the skin, joint or muscle biopsy samples of the patients, and on the basis of other findings, the present inflammation was considered to be of neurogenic origin. In an experimental study investigating neurogenic inflammation, patients with CRPS were observed to develop neurogenic inflammation much easily and found to have markedly more neuropeptide release. ${ }^{22}$

While the role of thrombocytes in the development of cardiovascular diseases and cancer has been extensively studied, their role in neuroinflammation appears to be rather overlooked. A review investigating the role of thrombocytes in neuroinflammation pointed out that the thrombocytes play major roles in inflammation and immunity. ${ }^{23}$ According to Gasparyan et al., ${ }^{24}$ MPV value is a parameter that varies according to proinflammatory and prothrombotic conditions. Elevated MPV was indicated as an independent risk factor for myocardial infarction and CVE, while a low MPV value was shown to be associated with the activity of inflammatory rheumatologic diseases. ${ }^{25-27}$

In a study comparing patients with $\mathrm{AD}$ and mild cognitive impairment to patients 
without dementia, Wang et al. ${ }^{13}$ reported that neuroinflammation caused by abnormal thrombocyte activation was the major underlying reason of these diseases. They found that patients with AD had lower MPV and PDW levels than those of the patients with mild cognitive impairment and without cognitive impairment. They explained that this difference might be due to the role of neuroinflammation in AD pathogenesis. Nonsteroidal anti-inflammatory drugs were shown to reduce the risk of $\mathrm{AD}$ development in the previous studies. ${ }^{28}$

In this study, hemoglobin levels were similar between the groups, while the patient group had significantly elevated MCV and RDW values. RDW indicates variations in size/volume of the red blood cells and it is a frequently used parameter for the differential diagnosis of anemia, particularly iron deficiency anemia. ${ }^{29}$ In a study investigating RDW values in MS patients, ${ }^{14}$ RDW was found to be higher in MS patients than healthy controls, and RDW values higher than $13.1 \%$ were shown to predict MS with a sensitivity of $70 \%$ and specificity of $85 \%$. Another study including patients with acute optic neuritis ${ }^{30}$ showed that RDW values were higher in the patient group when compared with controls.

Limitations of this study include its crosssectional design and relatively small sample size. In addition, lack of sophisticated parameters such as tumor necrosis factor alpha and interferon gamma are another drawback of the study.

In conclusion, the differences noted in the PDW, RDW, and MCV values between patients and healthy controls might support the potential role of neuroinflammation in the etiopathogenesis of CRPS type I. Prospective studies including larger sample sizes are required to support the practical use of the inexpensive, simple, easily accessible tests, such as PDW and RDW, in the early detection and/or differential diagnosis of CRPS type I.

\section{Declaration of conflicting interests}

The authors declared no conflicts of interest with respect to the authorship and/or publication of this article.

\section{Funding}

The authors received no financial support for the research and/or authorship of this article.

\section{REFERENCES}

1. Field J. Complex regional pain syndrome: a review. J Hand Surg Eur Vol 2013;38:616-26.

2. MaillardSM, DaviesK, KhubchandaniR, WooPM, Murray KJ. Reflex sympathetic dystrophy: a multidisciplinary approach. Arthritis Rheum 2004;51:284-90.

3. Schattschneider J, Hartung K, Stengel M, Ludwig J, Binder A, Wasner G, et al. Endothelial dysfunction in cold type complex regional pain syndrome. Neurology 2006;67:673-5.

4. EVANS JA. Reflex sympathetic dystrophy; report on 57 cases. Ann Intern Med 1947;26:417-26.

5. Hannington-Kiff JG. Intravenous regional sympathetic block with guanethidine. Lancet 1974;1:1019-20.

6. Latremoliere A, Woolf CJ. Central sensitization: a generator of pain hypersensitivity by central neural plasticity. J Pain 2009;10:895-926.

7. Sigtermans MJ, van Hilten JJ, Bauer MC, Arbous MS, Marinus J, Sarton EY, et al. Ketamine produces effective and long-term pain relief in patients with Complex Regional Pain Syndrome Type 1. Pain 2009;145:304-11.

8. Schwartzman RJ, Alexander GM, Grothusen JR, Paylor T, Reichenberger E, Perreault M. Outpatient intravenous ketamine for the treatment of complex regional pain syndrome: a double-blind placebo controlled study. Pain 2009;147:107-15.

9. Gokcen N, Basaran S. Complex regional pain syndrome and treatment approaches. Archives Medical Review Journal 2013;22:514-531.

10. Schinkel C, Scherens A, Köller M, Roellecke G, Muhr $G$, Maier C. Systemic inflammatory mediators in posttraumatic complex regional pain syndrome (CRPS I) - longitudinal investigations and differences to control groups. Eur J Med Res 2009;14:130-5.

11. Kozanoglu M.E, Sur S. Reflex sympathetic dystrophy syndrome. T Klin J PM \& R 2001;1:189-96.

12. Liang QC, Jin D, Li Y, Wang RT. Mean platelet volume and platelet distribution width in vascular dementia and Alzheimer's disease. Platelets 2014;25:433-8.

13. Wang RT, Jin D, Li Y, Liang QC. Decreased mean platelet volume and platelet distribution width are associated with mild cognitive impairment and Alzheimer's disease. J Psychiatr Res 2013;47:644-9.

14. Peng YF, Cao WY, Zhang Q, Chen D, Zhang ZX. Assessment of the Relationship Between Red Cell Distribution Width and Multiple Sclerosis. Medicine (Baltimore) 2015;94:1182.

15. Harden RN, Bruehl S, Stanton-Hicks M, Wilson PR. Proposed new diagnostic criteria for complex regional pain syndrome. Pain Med 2007;8:326-31. 
16. DiSabato D, Quan N, Godbout JP. Neuroinflammation: The Devil is in the Details. $\mathrm{J}$ Neurochem 2016 Mar 15.

17. Oyen WJ, Arntz IE, Claessens RM, Van der Meer JW, Corstens FH, Goris RJ. Reflex sympathetic dystrophy of the hand: an excessive inflammatory response? Pain 1993;55:151-7.

18. Drummond PD, Finch PM, Edvinsson L, Goadsby PJ. Plasma neuropeptide $\mathrm{Y}$ in the symptomatic limb of patients with causalgic pain. Clin Auton Res 1994;4:113-6.

19. Şentürk E, Esen F. Sepsiste immunoglobülin tedavisi ile kompleman inhibisyonu ve nöroproteksiyon. Türk Anest Rean Der Dergisi 2012;40:184-92.

20. Griffin WS, Sheng JG, Royston MC, Gentleman $\mathrm{SM}$, McKenzie JE, Graham DI, et al. Glial-neuronal interactions in Alzheimer's disease: the potential role of a 'cytokine cycle' in disease progression. Brain Pathol 1998;8:65-72.

21. Borchers AT, Gershwin ME. Complex regional pain syndrome: a comprehensive and critical review. Autoimmun Rev 2014;13:242-65.

22. Weber M, Birklein F, Neundörfer B, Schmelz M. Facilitated neurogenic inflammation in complex regional pain syndrome. Pain 2001;91:251-7.

23. Horstman LL, Jy W, Ahn YS, Zivadinov R, Maghzi AH, Etemadifar M, et al. Role of platelets in neuroinflammation: a wide-angle perspective. $\mathrm{J}$
Neuroinflammation 2010;7:10.

24. Gasparyan AY, Ayvazyan L, Mikhailidis DP, Kitas GD. Mean platelet volume: a link between thrombosis and inflammation? Curr Pharm Des 2011;17:47-58.

25. Şahin A, Yetişgin A, Şahin M, Durmaz Y, Cengiz AK. Can Mean Platelet Volume be a Surrogate Marker of Inflammation in Rheumatic Diseases? West Indian Med J 2015 May 6.

26. Bath PM, Butterworth RJ. Platelet size: measurement, physiology and vascular disease. Blood Coagul Fibrinolysis 1996;7:157-61.

27. Endler G, Klimesch A, Sunder-Plassmann H, Schillinger M, Exner M, Mannhalter C, et al. Mean platelet volume is an independent risk factor for myocardial infarction but not for coronary artery disease. Br J Haematol 2002;117:399-404.

28. McGeer PL, Schulzer M, McGeer EG. Arthritis and anti-inflammatory agents as possible protective factors for Alzheimer's disease: a review of 17 epidemiologic studies. Neurology 1996;47:425-32.

29. Ycas JW, Horrow JC, Horne BD. Persistent increase in red cell size distribution width after acute diseases: A biomarker of hypoxemia? Clin Chim Acta 2015;448:107-17.

30. Guclu H, Ozal SA, Pelitli Gurlu V, Birgul R. Elevated Neutrophil Lymphocyte Ratio in Recurrent Optic Neuritis. J Ophthalmol 2015;2015:758687. 